\title{
What Makes an Ex-Combatant Happy? A Micro-Analysis of Disarmament, Demobilization, and Reintegration in South Sudan*
}

\author{
Anup Phayal \\ University of Kentucky \\ Prabin B. Khadka \\ United Nations Peacekeeping Mission in Ivory Coast (ONUCI) \\ AND \\ Clayton L. Thyne \\ University of Kentucky
}

\begin{abstract}
Successful management of combatants through disarmament, demobilization, and reintegration (DDR) remains one of the main challenges of post-conflict peacebuilding. While DDR is meant to contribute to a secure post-conflict environment conducive to economic and political development, the success of DDR efforts remains mixed. Unlike previous work focusing on procedural aspects or post-conflict reconstruction and development, we shift the focus to understand microlevel conditions-economic, security, and ethnic concerns - that influence ex-combatants' satisfaction with DDR. We argue that ex-combatant satisfaction with DDR should increase as individual-level economic conditions increase, as security situations improve, and as ethnic tensions decrease. We test our expectations using an original data set collected with field interviews and surveys from 122 ex-combatants in South Sudan in 2011-2012. We find that participants are more satisfied when their income-generating activity is based on DDR job training and when the UN has a large presence in their area. Concerns about political instability and an abundance of firearms make ex-combatants less satisfied with DDR.
\end{abstract}

Civil wars are the most dangerous type of conflict in the international system. Beyond causing millions of deaths and displacements, civil wars spread diseases and offer opportunities for terrorist recruitment and organization (Collier, Elliott, Hegre, Hoeffler, Reynal-Querol, and Sambanis 2003). A civil war in North and South Sudan (1983-2005), which is the focal point for this study, saw 2.5 million deaths and 4.5 million refugees and internally displaced persons (UNHCR 2010). Given that around half of all civil wars are post-conflict relapses, recent scholarship has focused on ways to prevent civil war recurrence. Scholars agree that securing postwar peace requires settlements that address many elements, including protection issues, human rights, refugee repatriation, demobilization and disarmament of rebels, free and fair elections, and economic growth (Walter 1999, 2002; Stedman, Rothschild, and Cousens 2002; Hartzell and Hoddie 2003). Recognizing that policymakers under resource

Anup Phayal is a $\mathrm{PhD}$ candidate in the political science department at the University of Kentucky. He has worked as a UN peacekeeper in South Sudan. His research focuses on post-conflict peacebuilding.

Prabin B. Khadka works for the United Nations Mine Action Service (UNMAS) in Ivory Coast. When this research was carried out, he worked in the South Sudan. His research focuses on post conflict international interventions.

Clayton L. Thyne is an Associate Professor of Political Science at the University of Kentucky. His research focuses on domestic conflict/instability, coups d'état, democratization, and international education policy. His most recent work has been published in BJPS, JOP, ISQ FPA, and CMPS.

*We would like to thank Mark Peffley, Karen Mingst, Heather Bush, Dominique Zephyr, IR reading group at the University of Kentucky, ISQ editors, and anonymous reviewers for their comments. constraints face dilemmas in deciding how to address each element, a growing body of work argues for giving priority to disarmament, demobilization, and reintegration (DDR). It holds that satisfying ex-combatants constitutes a necessary first step in moving toward long-term goals, such as protection of the population and building legitimate governance (Stedman et al. 2002).

We build on this work and examine several factors that might influence an ex-combatant's satisfaction with DDR - including economic concerns, security concerns, external security guarantors, and ethnic reintegration. Our empirical tests focus on a recent case of DDR in South Sudan, which was a key component of the war-ending Comprehensive Peace Agreement (CPA) in 2005 (Verheul 2011:193). From the population of 10,350 individuals who underwent Phase I of DDR prior to August 2011, we completed interviews of 122 ex-combatants and conducted ten focus groups to gauge their level of support for DDR. We find the factors most strongly influencing their satisfaction level are also those that are most easily affected by policy. Satisfaction increases when DDR job training produces income-generating activity and when the UN has a large presence in the area. Meanwhile, concerns about political instability and an abundance of firearms make ex-combatants less satisfied with DDR.

Indeed, satisfaction directly relates to both the type of peace that develops following conflict and to the likelihood of war recurrence. Scholars understand that ending a civil war does not necessarily promote positive peace. For example, while the civil war may end in our data sets, a rise in crime level might indicate a failure of DDR (Kingma 1997:162; Paris 2001:771). These issues contribute to the recurrence of conflicts as dissatisfied 
former combatants make ripe recruitment targets for criminal and rebel groups (Berdal 1996:8). Ex-combatants who were dissatisfied with poor living conditions and a lack of regular salaries-conditions that they largely blamed on DDR-formed the M23 rebel group in the Democratic Republic of Congo (Wilen 2013:122). Their subsequent rearmament and fighting has wreaked havoc in the North Kivu region and lead to the displacement of 500,000 civilians (IRIN 2012).

Given the strong link between ex-combatant satisfaction and long-term peace in post-conflict states, researchers must understand as much as possible about how to implement programs that produce ex-combatant satisfaction with DDR. This is not to say that understanding excombatant satisfaction with DDR is the only, or even the foremost mechanism, deserving of study. Past work on power-sharing agreements and third-party security guarantees attests to the central importance of other factors in promoting postwar stability (Walter 2002; Hartzell and Hoddie 2003). Moreover, our sole focus on ex-combatant satisfaction after DDR only uncovers a part of the microlevel process. Successful reintegration of combatants also requires efforts among households and communities. Focusing on satisfaction of ex-combatants likewise uncovers only part of the process linking DDR with long-term peace; we can guarantee neither that a satisfied ex-combatant will be unwilling to re-join a rebel group, nor that an unsatisfied ex-combatant will return to fighting. Despite these limitations, we contend that DDR remains an integral component of postwar reconstruction. Excombatants who are satisfied with the DDR process are more likely to contribute to positive peace-building than their dissatisfied counterparts. Thus, although this study may uncover only one piece of the puzzle of postwar stability, its findings matter a great deal to policymakers and scholars alike.

\section{Past Studies of DDR}

DDR has been at the forefront of multidimensional peacekeeping efforts in recent years. It aims to "contribute to security and stability in post-conflict environments so that recovery and development can begin" (UN IDDRS 2010:24). Despite the overwhelming consensus that DDR serves as a necessary first step in assuring postwar peace, we know very little about the effectiveness of DDR. This lacuna has not gone unnoticed. Schulhofer-Wohl and Sambanis's (2010:4) assessment of DDR programs, for instance, critiques past research for focusing on implementation issues, technical details, and for promoting "best practices," rather than empirical assessment. Although we concur with this viewpoint, we also recognize that previous literature on DDR provides a solid foundation for continued study. We categorize this literature into three areas: (i) implementation manuals, (ii) the influence of DDR on stability and economic growth, and (iii) the microlevel determinants of DDR success. Although each area has improved our understanding of DDR, each also carries specific weaknesses that we hope to rectify.

Practitioner guides, manuals, and reports on DDR emphasize the procedural aspect of organizing DDR events (SIDDR 2006; UN IDDRS 2010). These documents contain extensive reports on lessons learned from previous DDR experiences, providing general and specific advice for future efforts. For example, the 2006 Stockholm Initiative on Disarmament, Demobilization and Reintegration (Stockholm Initiative on DDR (SIDDR) 2006:24) strongly endorses "the provision of what has come to known as a "transitional safety net" that enables the combatants to survive, take care of their families and cope while adjusting to their new statuses as a productive member of society." This report also contains considerations for individual-level participants. According to the report, "... different groups within the armed parties might require different approaches in a comprehensive DDR strategy. Reluctance of rank and file soldiers to lay down their weapons would probably have to do with their need for physical and economic security" (2006:19). Although these reports provide advice for conducting DDR based on the best information available, they have two main weaknesses. First, they focus almost exclusively on the day-to-day management of DDR programs, neglecting the viewpoints of those passing through DDR that likely influence future stability. Second, their bold statements and policy recommendations derive primarily from anecdotal evidence about DDR effectiveness.

The second body of work on DDR comes primarily from the academic community. Scholars step back from the day-to-day operation of DDR, focusing instead on how DDR fits within the broader framework of post-conflict stability. A growing body of work considers how DDR contributes to stability by managing spoilers - factions or leaders who use violence to undermine the peace process (Stedman 1997). For these scholars, DDR represents a development imperative that removes the means by which spoilers can reignite civil wars (Spear 2002; Humphreys and Weinstein 2007). When groups remain armed, violent politics remains the major concern undermining the peace process. This concern decreases with successful DDR programs, further highlighting the need to better understand ex-combatant perceptions of DDR to secure long-term peace.

Beyond the spoiler concern, a prominent debate has been on sequencing - what aspect should be given priority first: economic development or security? While some contend that promoting economic growth is the necessary first step toward peace (Collier, Hoeffler, and Soderbom 2008), others argue that demilitarization of excombatants provides the most fruitful path (Colletta and Muggah 2009). The empirical record seems to support the latter viewpoint. Brancati and Snyder (2012) show that when elections follow a UN DDR program, the likelihood of sustaining peace following civil conflicts increases by $60-84 \%$. This evidence aligns with academics (Paris 2004) and think-tanks (Bensahel, Oliker, and Peterson 2009) that argue for "institutionalization before liberalization." Taken together, this work highlights the important role DDR plays in creating environments conducive to development and sustainability. That being said, weaknesses still exist. Theoretically, scholars have largely neglected the massive variation in DDR programs that might explain DDR success and commonly use a dummy variable to capture DDR. While case studies tap into this variation, over-reliance on anecdotal evidence limits the generalizability of findings (Knight and Ozerdem 2004; Jennings 2007).

A third body of literature directly links to our study as it shifts the focus the study of DDR to individual level and emphasizes individual- and local-level issues. As mentioned earlier, scholars realize that the end of a civil war does not necessarily mean the beginning of a positive postwar peace. Because demobilization highly correlates with a rise in crime rates, societal violence, and civil war 
recurrence (Berdal 1996:8; Kingma 1997:157; Restrepo and Muggah 2009:35), several scholars have taken a microlevel approach that focuses on the post-conflict social environment. ${ }^{1}$ The goal here is to better understand the role that DDR plays in promoting a peaceful environment, and scholars like Colletta and Muggah (2009) have urged implementers to assure that DDR matches local needs and not the outsider's perspective. We now turn to our discussion of the factors that might explain these local needs, and how these needs influence participant satisfaction with DDR.

\section{Theory and Hypotheses}

The three groups of literature on DDR discussed above have one common attribute: They emphasize the objective determinants of DDR success, such as organizational aspects and war recurrence. However, DDR is a complex, long-term process for ex-combatants in their transition toward sustainable civilian employment and livelihoods (Kingma 2002). Paradoxically, while focusing on the long-term process, researchers lose sight of the key actor: the DDR participant. As seen in some unsuccessful DDR programs where crime level rose following DDR, the subjective evaluation of participants determines their choice to cooperate with DDR objectives. This leads us to shift our focus to the participant and ask: What makes an individual satisfied with DDR? Humphreys and Weinstein (2007) look at a similar puzzle and come up with several conclusions. After conducting research in Sierra Leone, they find that combatants with higher ranks and education levels, men, and ideologues are the most difficult to reintegrate into societies. The authors state, "Most important, we find little evidence at the microlevel that internationally funded programs facilitate demobilization and reintegration" (2007:531). This is profound, and in some ways better, than the contextual variables analyzed in earlier work because these findings speak to the preference of the participants themselves. We build on this work and focus on policy-oriented variables that determine satisfaction of DDR participants. Based on previous work from both the policy (Stockholm Initiative on DDR (SIDDR) 2006) and academic communities (Stedman 1997; Walter 2002), we expect security issues to play the strongest role in explaining satisfaction with DDR. However, the dearth of previous individual-level analyses on the determinants of ex-combatant satisfaction leads us to offer a more exploratory set of theoretical expectations. We initially focus on employment and income, and then move to security and ethnic reintegration.

\section{Employment, Income, and DDR Satisfaction}

A key motivation for ex-combatants against returning to fight is financial incentive. This viewpoint is consistent with economic models of civil war, which predict that the onset and recurrence of civil conflict increases with lower economic "opportunity costs" of fighting (Collier and Hoeffler 2004). DDR programs attempt to enhance economic opportunities of ex-combatants and prevent the resumption of hostilities since successful reintegration hinges upon ex-combatants' abilities to provide for their economic livelihoods and those of their dependents

\footnotetext{
${ }^{1}$ See Muggah, Molloy, and Halty (2009) edited volume for several recent microlevel studies on DDR. Also see Muggah (2010) for a superb literature review on the development of policy and research related to DDR.
}

(Spear 2002). Therefore, DDR programs must focus not only on direct payments of cash during the disarmament phase, but also on improving ex-combatants' prospects of employment through DDR training. Work focusing on DDR in Liberia supports this contention, finding that unsuccessful DDR in 2003 was largely due to dissatisfaction among the ex-combatants about their personal economic situation (Jennings 2007; Spear and Harborne 2010). These scholars conclude that the transition to postwar stability would have been smoother if the DDR program had provided ex-combatants with jobs and satisfactory incomes.

We focus on two features of DDR to better understand its influence on ex-combatant satisfaction: income and employment. At the simplest level, we expect satisfaction with DDR to increase as incomes of ex-combatants increase. This is because participants will see DDR as part of the process that enabled them to successfully reintegrate into society. Because DDR is part of a larger process, we also consider specific skills that ex-combatants acquire during the training phase. While all ex-combatants who underwent DDR in South Sudan received job training in areas such as operating small businesses, agriculture, automotive repair, and carpentry, not all participants used their training to improve their economic situation. This was primarily due to disconnects between the training offered and the local-level economic environment faced upon reintegration. One might have been trained in carpentry during DDR, for example, only to find little demand for this skill upon reintegration. In situations like these, the skills learned during DDR are unlikely to yield a positive reaction to the process overall. This discussion leads to our first set of hypotheses:

\begin{abstract}
Among ex-combatants who have undergone DDR, satisfaction with DDR should increase as incomes increase (Hla), and if individuals were able to continue the profession related to the vocational training they received $(\mathrm{H} 1 \mathrm{~b})$.
\end{abstract}

\section{Security and Firearm Availability}

Security is paramount to understanding postwar stability. As Kalyvas (2006:146-172) explains, civil wars produce environments where fear, lack of information, coercion, intense emotional reaction, incentive, and the low cost of violent means drive individuals to pursue violence. This legacy of mistrust continues long after the cessation of hostilities. It heightens the security dilemma at the individual level, forcing ex-combatants to fear and mistrust the intentions of others. This lack of trust can hinder enrolling in DDR in the first place, and satisfaction levels likely depend on perceptions of the security situation once participants exit the program.

The assurance of security to former fighters is core to their volunteering for DDR, as the "disarmament" component means to reduce the number of weapons in society and "make a rapid re-mobilization for violence harder" (Schulhofer-Wohl and Sambanis 2010:7). The widespread availability of weapons threatens the security of ex-combatants, and DDR attempts to ameliorate this threat through the collection and removal of weapons from society. In an ideal scenario where ex-combatants disarm and then reintegrate into peaceful societies with few weapons, we would expect the disarmed individuals to be satisfied with laying down their weapons because doing so would not put them in a disadvantaged position. However, we 
expect satisfaction to decrease among disarmed ex-combatants if firearms are widely available in society. Two mechanisms support this contention.

First, disarming individuals in a heavily armed society should decrease satisfaction with DDR because giving up arms increases fears of getting attacked (Walter 2002:21). Since rebel groups emerging from civil wars will have only recently stopped using armed force, the question of who will "exercise control over the instruments of coercion are likely to be central" (Hartzell and Hoddie 2003:320). In South Sudan, which has one of the highest ratios of guns per capita in the world, firearms help secure and protect livelihoods. Cattle rustling, for instance, is one of the foremost security problems in South Sudan (Gettleman 2012). Given the lack of a strong, formal policing mechanism in the country, individuals likely see self-armament as their best option to assure livelihoods for themselves and their families. Disarming ex-combatants and then reintegrating them into a society flooded with weapons, particularly after they have formally severed their existing military and social networks through DDR, likely makes the DDR participant unsatisfied with DDR overall.

While we expect satisfaction to decrease among disarmed individuals as the security situation worsens or when others have abundant firearms, we expect these two factors to interact in a unique way. The notion that disarmed ex-combatants will be dissatisfied with DDR when firearms are widely available in the community likely holds only when the security situation is stable. As before, this is because disarmed individuals may still worry about the security of themselves, their families, and their property. However, in some areas, the security situation becomes so dire that disarmed individuals become willing to expend their resources on re-armament. We have seen such situations arise due to cattle rustling in Warrap state of South Sudan, for example, and ethnic fighting in Jonglei (Aleu 2010; Pendle 2012). When these dire situations arise, we expect DDR participants to become more satisfied with the widespread availability of firearms because they can more easily rearm in such environments. Taken together, this discussion leads to our next set of hypotheses, which focus on general security concerns, firearm availability, and the interaction of these two factors:

\begin{abstract}
Among ex-combatants who have undergone DDR, satisfaction with DDR should decrease as security concerns increase (H2a), and if there is an abundance of firearms in their area of reintegration (H2b). However, the negative influence of firearm availability on satisfaction with DDR should lessen as security concerns increase (H2c).
\end{abstract}

\section{External Security Guarantors}

Scholars recognize the importance of security concerns facing ex-combatants and have sought ways to explain how individuals can be disarmed while still feeling secure to establish long-term peace. One of the foremost solutions to this dilemma is the introduction of external security guarantors. As Walter (1999:137) explains, warring factions have a difficult time credibly committing to DDR unless a third-party can guarantee the security of those who disarm. Civil war settlements hold stronger when third parties enforce the agreements (Walter 1997:341; Walter and Snyder 1999:27). This is because third parties can "guarantee that groups will be protected, terms will be fulfilled, and promises will be kept" (Walter 1997:340). We expect that the mechanisms at work for postwar peace also relate to ex-combatant satisfaction. DDR participants should be more satisfied if external security guarantors are present in their area of reintegration.

The United Nations Mission in the Republic of South Sudan (UNMISS), which approved up to 7,000 military and 900 civilian police personnel to provide security, acts as the primary external security guarantor in South Sudan. Its mandate ensures that the guarantor can use force if necessary, and that the UN has sufficient military capabilities to punish violators. While the size and scope of UNMISS is large relative to other UN peacekeeping operations, the number of peacekeeping troops (about one-fourth the size of the New York Police Department) coupled with the sheer size of South Sudan (roughly the size of Texas) makes it impossible for peacekeepers to secure all areas. Thus, many former combatants have reintegrated into areas with little UN presence. We expect these people to be less satisfied with DDR compared to those who see "blue helmets" frequently. This leads to our third hypothesis:

\begin{abstract}
Among ex-combatants who have undergone DDR, satisfaction with DDR should increase as the presence of security guarantors in their area of reintegration increases (H3).
\end{abstract}

\section{Reintegration and Ethnic Tensions}

One of the microlevel contextual factors that determine the success of DDR is the level of homogeneity in the society (Colletta and Muggah 2009:8). In heterogeneous societies, and especially those where ethnicity remains salient, successful reintegration of former combatants remains an exceedingly difficult task. The job becomes even more difficult when reintegrating ex-combatants are of different ethnicity compared to the majority in the target society.

Combatants frequently choose to avoid their prewar homes and reintegrate into ethnically dissimilar locations for a variety of reasons. The simplest reason is that excombatants frequently have no home to return to, as conflict often destroys villages and homes become dilapidated during the war. Floods of refugee repatriation also often follow the end of fighting. When the Equatorians fled the civil war in South Sudan, for example, the majority Dinka ethnic group quickly occupied the vacated areas. The repatriation of Equatorians after the fighting ended drastically increased competition for space and resources (Branch and Mampilly 2005). Furthermore, bitter ethnic tensions that existed before the war are often shelved during the conflict, as ethnically disparate opposition movements join together to fight a common foe. These tensions can quickly re-emerge once fighting ends, as we have seen with repeated waves of violence between the Murle and Nuer ethnic groups in South Sudan (Gettleman 2012). Finally, many former combatants are fearful of retribution from their home community for heinous acts they committed during the conflict (STHLM 2010). Each of these factors leads many ex-combatants to settle away from their prewar homes after undergoing DDR, which can lead to dissatisfaction for a number of reasons. 
First, while becoming financially stable is difficult for any ex-combatant, those integrating into communities wherein another ethic group dominates face additional challenges. They must compete for employment with workers who the dominant class of employers frequently favors, and face difficulties starting businesses that compete with those of the dominant class (Beswick 2004:175184). Second, ex-combatants face a difficult time finding positions of leadership, as outsiders are often shunned and juniors who did not fight have matured into positions of community and party leadership (Pun 2012). Third, integration into communities with foreign lifestyles and cultural practices increases feelings of isolation. In South Sudan, this is particularly true for non-Dinka females who married Dinkas during the war and were forced to settle into Dinka communities after DDR (Small Arms Survey 2011). As the primary purpose of DDR is to support recovery and development, individuals facing these difficulties often blame DDR for not only failing to provide adequate education and skills necessary for successful employment, but also for providing little to support their integration into ethnically disparate communities. This leads to our final hypothesis:

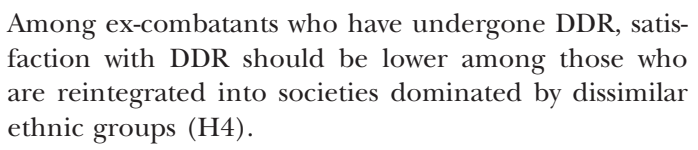

\section{DDR in South Sudan}

The history of Sudan is one of civil conflict. The first Sudanese Civil War began immediately prior to gaining independence in 1955 and lasted until 1972. Unresolved issues led to a recurrence of the conflict from 1983 to December 2004, making the second Sudanese civil war one of the world's longest conflicts. The war began coming to a close with the signing of the Comprehensive Peace Agreement (CPA) in 2005. DDR became a primary focus of the CPA, as the Government of Sudan and the SPLM agreed to demobilize their combatants (Verheul 2011). ${ }^{2}$ Militias in the South were either integrated into the SPLA or demobilized and reintegrated into society.

The first phase of DDR targeted SPLA combatants. Supported by the UN and other partners, the SPLA attempted to identify 90,000 personnel for DDR. After initially "diagramming" ex-combatants (a process of profiling and sensitization as a part of demobilization), reintegration followed. A civilian training process (CTP) - which taught the former combatants skills like literacy, numeracy, conflict management, and civic education-highlighted the reintegration phase. UNMISS led the DDR process as part of the broader peace support operations. Phase 1 DDR concluded in April 2011, and provision of reintegration support formally closed at the end of the year.

The next "Phase 2 DDR" is one of the key priorities of the South Sudan Development Plan for the broader peace-building process. The break between the two phases offers a unique opportunity to evaluate the success and failures of the earlier phase and inform policymakers working with DDR both in South Sudan and elsewhere.

\footnotetext{
${ }^{2}$ The SPLA (Sudan People's Liberation Army) and SPLM (Sudan People's Liberation Movement) are commonly lumped together in the literature as "SPLA/M," as these terms could be used interchangeably during the civil war to refer to the primary southern rebel force. Today, the SPLA is the official army, while the SPLM is the ruling party of South Sudan.
}

Recent events show that the security situation remains highly fragile, posing a serious challenge to peacebuilding in South Sudan and the broader region. While DDR is one of the leading components of the broader Security Sector Reform (SSR) in the country, SPLA membership seems a more attractive option than volunteering for DDR due to weak economic incentives and security concerns.

Focusing on South Sudan yields two primary advantages. First, it represents the most recent case of multilateral DDR efforts. International actors involved have invested considerable time and effort into planning and implementing DDR based on experiences and lessons of over two decades. Thus, this case provides the best environment for evaluating the most recent trends in DDR. Second, unlike previous cases, availability of data from the actors implementing DDR allows us to control for the variation in how DDR was implemented. We know exactly where and how many peacekeeping forces the UN deployed at the county level, for example, and where excombatants de-mobilized. By supplementing this information with our interviews, these data allow us to examine microprocesses that have been captured primarily at the state-level in previous studies.

While the advantages to studying South Sudan are many, we do not want to overstate what might be learned from our study. DDR programs vary greatly on a number of factors, including the degree of government and rebel participation, financial resources, and involvement of external actors (Schulhofer-Wohl and Sambanis 2010). Such heterogeneity makes it difficult to claim that any single DDR experience represents all others. And while most DDR cases have an uneven record, DDR in South Sudan has been criticized for having a particularly poor record. Problems include slow implementation, mismanagement and inefficiency, uneven participation by key actors, and inability to address heterogeneity among actors (Muggah et al. 2009; Brethfeld 2010; Kron 2010). Likewise, the way that the war ended in South Sudan, including continuing ethnic tensions and eventual independence, is unique. Previous work has shown that the way a war ends profoundly influences the dynamics of DDR (Lamb and Dye 2009:4), with a "key" aspect in DDR success being "whether the receiving community is willing to accept the ex-combatant unreservedly" (Alusala and Dye 2010:8). Thus, while studying DDR in South Sudan offers several clear advantages, we should also temper our expectations about what our analyses can provide.

\section{Survey Design and Analysis}

South Sudan is a vast, sparsely populated area, and moving about is difficult even under the best of conditions. Nevertheless, an adequate test of our hypotheses requires a sample generated as randomly as possible among the population of DDR participants. We attempted to achieve this sample by following two steps.

First, we obtained county-wise summary statistics listing the population of 10,350 ex-combatants who underwent DDR before December 2011 from the South Sudan DDR Commission. We could not gain access to names from which to draw a random sample from this initial list. This was unfortunate because important variations in DDR occurred across the seven states where DDR took place. For example, the 3,499 ex-combatants who underwent DDR in Lakes State were offered more extensive training opportunities than were the 29 participants in Warrap. Thus, our initial step was to stratify the population from each state by 


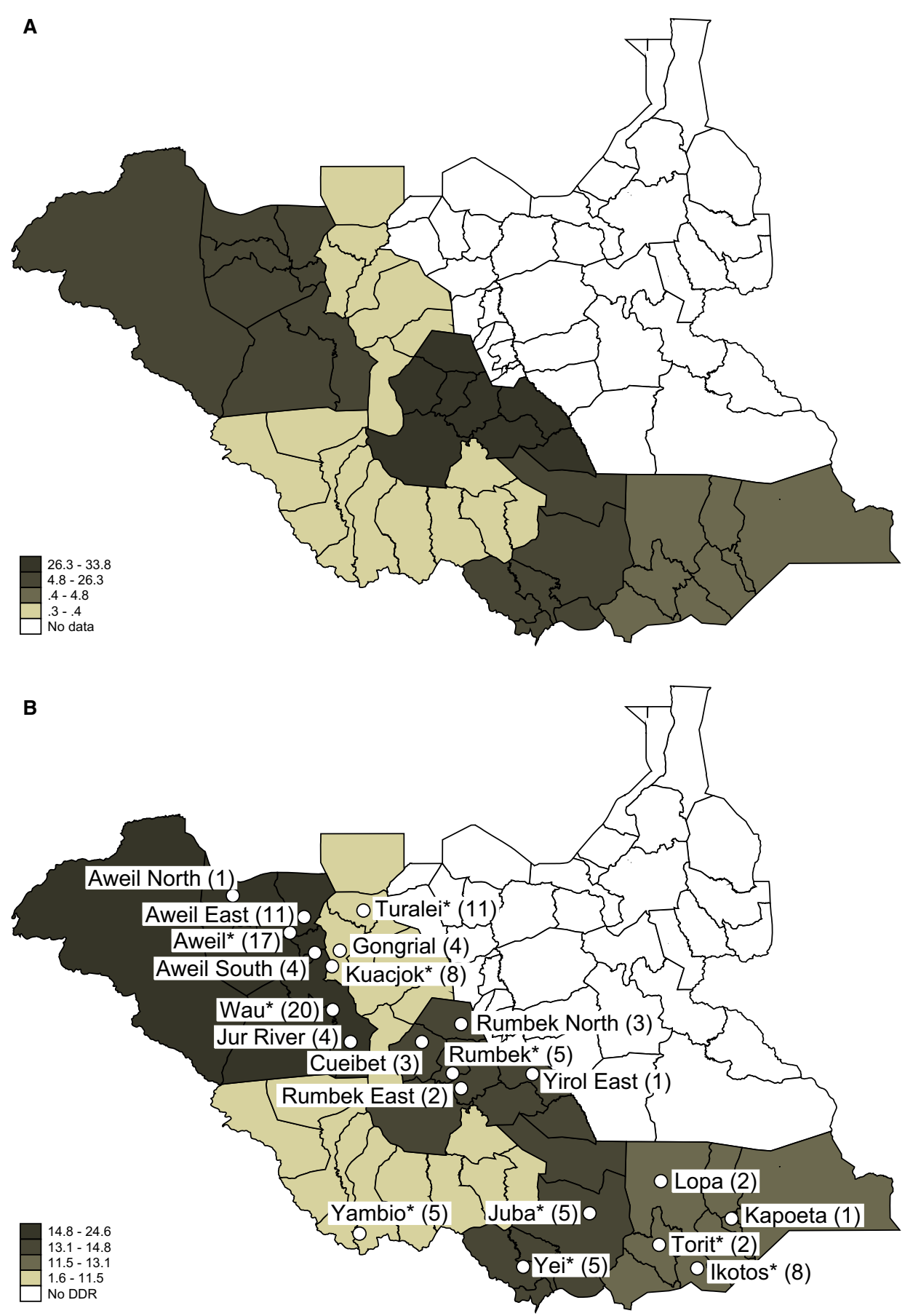

FIG. 1. Comparison of Population and Survey Sample. (a) DDR Location, Population $(n=10,350)$. (b) DDR Location, Sample $(n=122)$ Note. Legends show percentages by state: (individuals interviewed/122). Towns marked with * are those with UNMISS offices where interviewers collected lists for random sampling. Numbers in parentheses are completed surveys in each location.

calculating the percentage of total DDR participants who underwent DDR in each state, which is represented in Figure 1a. We then used these percentages as targets for how many DDR participants to survey in each state. For example, the 3,499 DDR participants in Lakes State comprised $38.5 \%$ of total DDR participants, which established our target goal for surveys to come from this area. ${ }^{3}$

\footnotetext{
${ }^{3}$ This stratification process is similar to that of Muggah and Bennett (2009), who used a proportional size sampling strategy based on the concentration of returned Ethiopian veterans from the cross-border war with Eritrea.
}

Our second step was to randomly select DDR participants among our state-stratified categories. While we could not obtain a consolidated list of names from the central DDR office, we were able to obtain this information from all ten of the locations where DDR programs took place. Thus, upon entering a community where DDR was conducted, interviewers contacted the local representative from the UNMISS DDR Office. These representatives had information (names and locations) about ex-combatants in the state who underwent DDR. Once the interviewers obtained this information, they randomly 
selected participants based on the predetermined stratification strategy. The interviewers then located these individuals to conduct surveys. We present precise interview locations in Figure 1b. ${ }^{4}$ Most individuals were conveniently located near the 10 areas where they underwent DDR because these areas provided the best job prospects. Interviewers also traveled to several remote locations to locate participants who moved away from these locations. In all, 21 locations were visited to conduct interviews.

A pair of interviewers, including one of the authors and a translator from South Sudan, conducted the interviews. Their affiliation with an international NGO for removing Explosive Remnants of War (ERW) provided them with access to all areas of South Sudan since it is littered with such items. Residents in each area had grown accustomed to working with representatives of the organization, which helped ease potential concerns about outsiders entering the community. The final tally included 122 completed surveys. By first stratifying the sample and then randomly selecting the participants once on site, our sample provided considerable variation on factors that are likely to influence one's satisfaction with DDR. ${ }^{5}$

Before moving to our analyses, four primary concerns with the survey approach should be addressed. First, participants may provide inaccurate information if they are under pressure from an observer or have confidentiality concerns. We expect little bias due to these issues. Both the interviewer and the translator have extensive field experience in the region, making them aware of cultural considerations necessary to assure that interviews were conducted in an unbiased and confidential manner. Awareness of cultural norms led the interviewers to conduct most interviews in public areas or in the participant's workplace. No interviews were conducted among people who might pressure participants to alter their answers (for example, husbands or public officials). The nature of the questions also assured honest answers, as no questions were asked that would be deemed inappropriate or controversial in the participant's community.

Second, after being informed of the purpose of the interview and the requirements for participation, only 10 potential interviewees declined to participate. For those who declined to participate, all requested that the interviewers return at a more convenient time.

Third, we see in Figure 1 that the researchers were unable to obtain the perfect number of participants based on state-stratification. While the goal of obtaining $26.3 \%$ participation was nearly met with a $24.6 \%$ participation rate in Northern Bahr Ghazal, for instance, participants were oversampled in Central Equatoria (10.6\% target, $14.8 \%$ actual) and undersampled in Lakes $(33.8 \%$ target, $13.9 \%$ actual). These missed targets developed because the interviewers were sometimes unable to meet the target percentages when they entered an area for survey. For example, once interviewers arrived at remote locations in Lakes, they found fewer ex-combatants in the area than expected. We are unconcerned about this

\footnotetext{
${ }^{4}$ DDR was conducted in exactly 10 locations in South Sudan (those marked with $\mathrm{a} *$ in Figure $1 \mathrm{~b}$ ), and interviewers visited each site to access a full list of DDR participants from each location. To be sure, we summed the total numbers from each of the 10 localized lists, which added up to 10,350 . This total matches the total given in the summary statistics from the central DDR office, verifying that we were able to randomly sample the entire population by piecing together the lists provided by the local offices.

${ }^{5}$ We provide summary statistics and bivariate relationships for all measures in the Appendix.
}

leading to bias, however, because our final sample includes considerable variation to control for potential biases that might arise from over- or undersampling, and robustness checks address these issues by weighting observations using the target and sample stratification percentages.

Finally, our efforts to obtain a random sample led to a much smaller sample than we could have obtained using a more convenient approach. While we would have preferred a much larger sample, three issues help alleviate concerns with studying only 122 surveys. First, a small N should only inflate standard errors, biasing away from Type I error. Second, as shown in the Appendix, our control variables capture a great deal of heterogeneity among the respondents. Individual-level variation is captured with measures for age, rank, gender, education, and ethnicity, and community-level variations include wealth and instability. Finally, our statistical analyses are reinforced and clarified with focus group discussions, giving us confidence that our sample, while admittedly small, allows us to speak to more general viewpoints about DDR in South Sudan.

\section{Dependent Variable and Estimation Technique}

The dependent variable is the level of satisfaction with DDR among ex-combatants who underwent Phase 1 DDR. Before asking a respondent about their level of satisfaction, we initially sought to assure that all respondents gauged their level of satisfaction similarly. We first were concerned that ex-combatants might have developed different prior expectations about the purpose of DDR. If so, we might expect those with lofty prior expectations to be less satisfied with the outcome of DDR vis-à-vis those with meager expectations (Kilroy 2012). Second, we were concerned that respondents might gauge satisfaction on a variety of terms. For example, they might consider whether DDR improved their individual situation, household situation, was fairly administered, or may simply capture general optimism about the postwar climate. Thus, before being asked to gauge their level of satisfaction with DDR, interviewers first asked respondents to explain what they know about the purpose of DDR. All respondents provided answers that were consistent with the UN's stated objective that DDR should "contribute to security and stability in post-conflict environments so that recovery and development can begin" (UN IDDRS 2010:24). This consistency is unsurprising because the UN and its partners repeatedly informed ex-combatants of the purpose of DDR in an effort to get participant "buy in." For our purposes, the consistency assures that "satisfaction" can reasonably be assumed to mean the same thing across respondents. ${ }^{6}$

Participant satisfaction with DDR is assessed with the question, "How satisfied are you with the DDR process?" to which three possible responses were recorded: not satisfied $(13.9 \%)$, somewhat satisfied $(49.2 \%)$, and very satis-

\footnotetext{
6 There is no way that we can guarantee that all respondents view "satisfaction" on the same terms. Although this is not unique to surveys that ask subjective questions, we attempt to assure that our results are as robust as possible by controlling for a variety of measures to help isolate the influence of our primary independent variables on the respondent's level of satisfaction with DDR. These include security optimism, education, and rank to capture individual-level expectations, and cereal production and killings to capture the economic and security environment at the community level.
} 
fied $(36.9 \%)$. Given that the dependent variable is ordinal, we use ordered logit to test our hypotheses.

\section{Explanatory Variables}

To test our first set of hypotheses, we assess participants' income (H1a) and job training (H1b). Our first measure, monthly income, is captured by asking ex-combatants their monthly earnings in South Sudanese pounds $($ mean $=661.6, S D=620)$. None of our respondents received payment during the conflict, so income for each respondent can be assessed relative to the same intra-war baseline of zero. Our next measure, job training, is a dummy-variable-coded $1(54.1 \%)$ if the respondent continued the profession related to the vocational training received during DDR.

The next set of independent variables captures the security situation (H2a) and firearm availability (H2b). Two measures capture the respondent's view of the security situation. ${ }^{7}$ The first, political instability concern, is a dummy-variable-coded $1(23 \%)$ if the respondent chose "political instability" as a top concern. The second measure focuses on local issues. Cattle rustling concern is a major concern in vast areas and was reported as a primary concern among $25 \%$ of our survey participants. Perceptions of firearm availability are assessed on a threepoint scale by asking respondents, "How difficult it is to get weapons in the society," "difficult" (coded 1, 54\%), "moderate" $(2,30 \%)$, or "easy" $(3,16 \%) ?^{8}$ Finally, we formed interaction terms by multiplying the two security concern measures with firearm availability to test our hypotheses that perceptions of firearm availability have a weaker impact on DDR satisfaction as security concerns increase $(\mathrm{H} 2 \mathrm{c})$.

The next variable focuses on the presence of an external security guarantor (H3). Although the government of South Sudan is currently taking control over the security situation in the country, at the time of our survey the UN performed the majority of peacekeeping. Thus, we include a measure called UN presence, which is the number of UN peacekeepers in each county normalized by its population $($ mean $=5.6, S D=6.1$; South Sudan Statistical Yearbook 2011). We expect this measure to increase the respondent's satisfaction with DDR. Our final measure, return to area of origin, is a dummy-variable-coded $1(74 \%)$ if the ex-combatants were reintegrated to the same area where they originally came from before joining the SPLA. We expect this measure to be positive to support our final hypothesis (H4).

\section{Control Variables}

Our models control for three sets of factors that may influence one's satisfaction with DDR. As discussed earlier, the similarities in how respondents view the purpose of DDR give us confidence that our dependent variable

7 "Political instability concern" and "cattle concern" came from an openended survey question asking respondents to list their top-3 concerns. Responses were grouped into 14 categories, and the measures came from selecting respondents that answered by mentioning either political instability or cattle rustling as primary concerns.

${ }^{8}$ We also tested a community-level measure to capture firearm availability. This measure is the mean response for each state to the firearm availability question $($ mean $=1.61, S D=0.39$ ). This measure provides substantively identical results to the individual-level measure, helping alleviate the concern that the individual-level measure might be tapping into more general pessimism about the DDR process. captures a similar concept across respondents. However, our measure may still capture the individual's underlying optimism or pessimism about the postwar climate. Thus, to assure that we are isolating the influence of our independent variables on ex-combatant satisfaction, our first set of controls includes measures meant to capture respondents' general feelings toward the postwar situation. Our first measure, Security optimism, is a dummy-variable-coded $1(48 \%)$ if respondents think that the security situation is improving. ${ }^{9}$ Next, given that DDR happened in consultation with the Dinka-dominated SPLA, however, our measure may still capture the individual's toward government-sponsored programs. Dinka is a dummy variable if respondents are Dinkas (75\%).

Our second set of control variables captures the ease at which individuals reintegrate into society. Our efforts here stem from the interplay between ex-combatant needs and variation in how ex-combatants are received by their communities, which has been found in past work to be crucial to DDR success (for example, Lamb and Dye 2009). Our Dinka measure captures part of this, as transitions for Dinkas should be easier because Dinkas dominate South Sudan in terms of leadership and income. We add four other control variables. The first, education, is captured with a measure asking whether the participant had any formal schooling $(62 \%)$. We expect higher satisfaction among those with formal schooling because their education should allow them to more easily obtain jobs following DDR. Second, we control for age (mean $=43$, $S D=11)$, predicting younger ex-combatants to have easier times integrating into communities during a time when they would have been leaving their homes had the war never taken place. Third, we control for the rank that the DDR participant had during the conflict with an ordinal measure ranging from 1 (private) to 8 (colonel). We expect higher satisfaction among participants with higher ranks because in a SPLA/SPLM dominated society, their privileged position likely continues after the conflict ceases (Mores 2013). Additionally, rank is a reasonable proxy for performance and aptitude more generally, as skilled individuals are likely to be successful in both theaters of conflict and peace. Finally, we include a dummy variable for Males (53\%), expecting males to integrate more easily into society.

Our final set of control variables captures how well the community is doing overall. The first, Killings (mean $=0.15, S D=0.36)$, are county-level data that capture the number of conflict-related deaths per thousands of individuals (OCHA 2009-2011). The second, Cereal production $($ mean $=14,440, S D=12,727)$, proxies the level of wealth in each county (NBS 2009-2011). Like killings, it also captures security because crop production decreases dramatically with violence (Caruso, Khadka, Petrarca, and Ricciti 2012). These measures are important for three primary reasons. First, the community is integral to successful reintegration. Communities doing poorly will likely reject their new members in both social and economic terms, making ex-combatants dissatisfied. Second, the expected influence of several of our individual-level measures (particularly monthly income and job training) on satisfaction might depend on the respondent's relative position within the community. Third, it is possible for UN presence to be biased if the UN purposefully chooses

\footnotetext{
${ }^{9}$ This measure comes from a survey question that asks whether the respondent views the security situation as improving $(47.5 \%)$, getting worse $(21.3 \%)$, or about the same $(31.2 \%)$ today as compared to 2 years ago.
} 
to station personnel at locations where they expect to see either stability or instability, making it necessary to control for observed community-level characteristics to isolate the influence of UN presence on DDR satisfaction (Caruso et al. 2012).

\section{Results}

Our first two hypotheses focus on personal economic situations, predicting that higher income (H1a) and continuation of employment consistent with DDR job training (H1b) should increase satisfaction with the DDR. We find split support for our expectations. While the coefficient for income is insignificant in each model, we see the expected positive and significant effect for job training $(p<.033)$. This is promising. DDR is one of many components that influence postwar income, and respondents neither credit nor blame DDR for their economic situation. ${ }^{10}$ When asked about job training, though, we see that respondents who used DDR training to gain employment are significantly more likely to view DDR in a positive light.

We present the substantive effects to the right of Table 1. These values indicate how the likelihood of support for DDR changes as each independent variable increases from its minimum to maximum value while holding all other variables constant (means and modes). ${ }^{11}$ Regarding job training, we see that the likelihood of being "very satisfied" is .474 for those who received useful training as part of DDR, and .241 for those who were unable to use their training to obtain employment. The difference between these values (FD) equals +.233 , meaning that the likelihood of being very satisfied increases by .233 on average if the respondent received useful job training. For ease of interpretation, we present the data for first differences for all significant variables in Figure 2. ${ }^{12}$

We next turn to our discussion of security (H2a) and firearm availability (H2b). Although the coefficient for "Cattle rustling" is insignificant, we see that concerns with political instability $(p<.041)$ and the widespread availability of firearms $(p<.003)$ significantly decrease satisfaction with DDR. The likelihood of a respondent being very satisfied with DDR decreases by .246 when an excombatant views political instability as a top concern. The substantive effect for firearms is even stronger, representing the strongest influence of any measure in our model. The likelihood that a respondent is very satisfied with DDR plummets by .379 when they perceive firearms as being readily available. This demonstrates the importance of demobilization efforts beyond DDR participants, as disarming individuals and then asking them to reintegrate

\footnotetext{
${ }^{10}$ Humphreys and Weinstein's (2007) analysis of DDR in Sierra Leone finds that poor ex-combatants are more successful at reintegration than wealthy ones. Although we find a null effect and look at a somewhat different outcome, taken together these studies agree that individual wealth does not have the strong positive link to DDR success that conventional wisdom suggests.

${ }^{11}$ We used the Clarify program to estimate the predicted values and first differences reported in Table 1 and Figure 2 (King, Tomz, and Wittenberg 2000; Tomz, Wittenberg, and King 2003).

${ }^{12}$ One peculiar point about Figure 2 is that none of our relationships show a clean linear effect. This is because our dependent variable is not distributed equally across all categories. Only 17 (13.9\%) respondents answer with "not satisfied," which means that raw probabilities (and their first differences) are small regardless of how the independent variable varies.
}

into a heavily armed society is likely to decrease satisfaction with DDR.

We also hypothesized a potential interactive effect between firearm availability and security concerns (H2c), expecting the negative influence of firearm availability on DDR satisfaction to weaken as security concerns increase. We test this by interacting Firearm availability with Political instability concern (Model 2) and Cattle rusting concern (Model 3). We also present the results graphically in Figure 3, which illustrates results that are consistent with our theoretical expectations. The negative effect of firearms on satisfaction is significant only when the respondent has neither political nor cattle rustling concerns. This negative effect goes away when the security situation worsens, which is likely because re-armament becomes much easier in a society flooded with weapons. We probe this finding further in our focus group analyses.

Our third hypothesis predicted that respondents would view DDR more favorably if there was a strong presence of external security guarantors in their area. We test this by examining how the presence of UN personnel influences perceptions of DDR, finding strong support for our expectations $(p<.033)$. In substantive terms, the likelihood that an ex-combatant is very satisfied increases by .354 as the UN presence increases from its minimum to maximum value. This represents the strongest positive influence in the model, supporting work that stresses the importance of external security guarantors for postwar peace (Walter 1999, 2002; Brancati and Snyder 2012). Importantly given that the UN does not randomly choose where to send troops, this result holds when controlling for two measures that capture the economic (Cereal production) and security (Killings) concerns that likely guide UN troop placement decisions. Regarding our final hypothesis, we find no support for the idea that people are more satisfied with DDR when they return to their area of origin.

Finally, we find some support for our expectations for the control variables. Our measures for age, gender, rank, killings, and cereal production produce insignificant findings. However, respondents with some education are generally less satisfied with DDR, which is consistent with previous work from Humphreys and Weinstein (2007). Meanwhile, satisfaction increases among both Dinkas and those who think the security situation is improving. We ran two additional analyses to assure that the results presented above were insensitive to our estimation technique. We first controlled for all states from Figure 1 with dummy variables and clustered our standard errors by state. Neither made an appreciable difference in our results. Second, we weighted our observations by state, using the percentages from Figure 1 to calculate weights. Once again, weighting our observations changed our findings very little.

\section{Focus Group Illustrations}

After deriving preliminary findings, researchers returned to ten sites to probe DDR participants on a number of issues. Researchers decided against randomly selecting individuals to participate in focus groups. Non-Dinkas are unlikely to participate in groups that include Dinkas, for instance, and females are unlikely to participate around males. Two focus groups were conducted in each of the non-Dinka-dominated Eastern Equatoria and Central Equatoria states. Two others were conducted in each of the Dinka-dominated Northern Bahr Ghazal, Western 


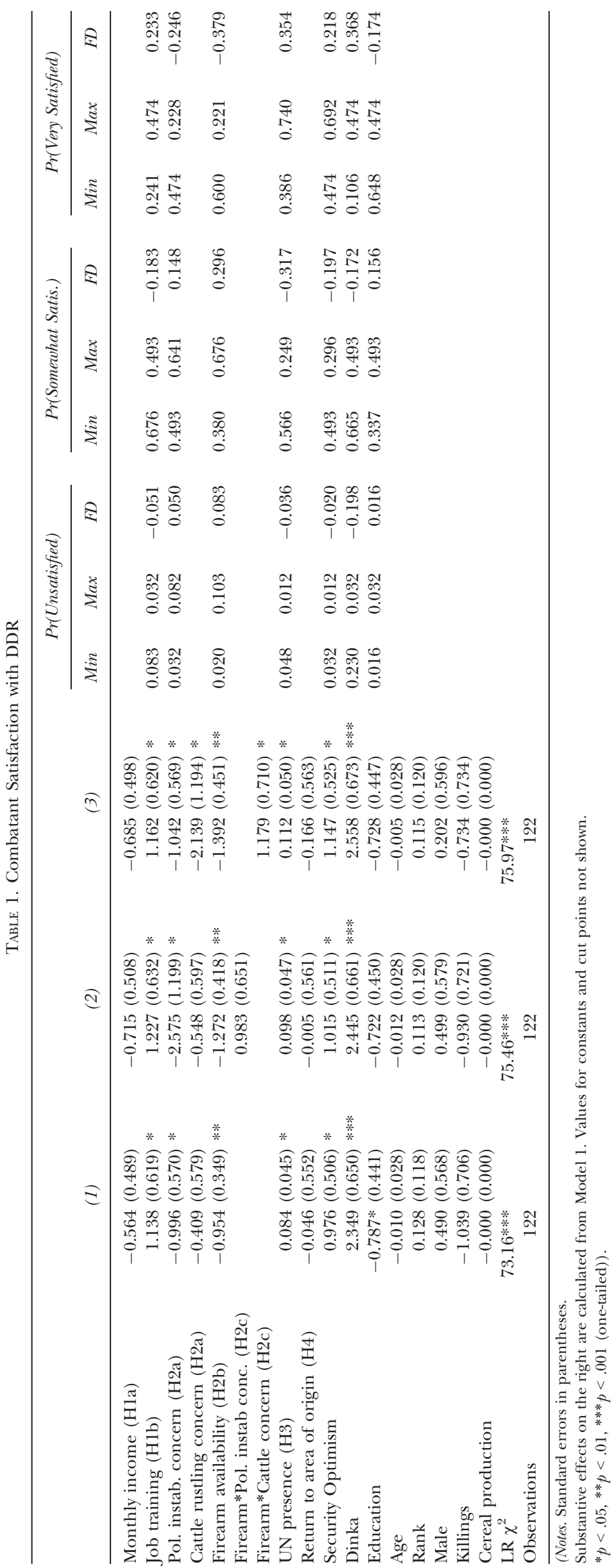


Bar-el Gazhal, and Warrap states. Groups were diversified based on gender, age, and ethnicity. Although the focus groups were appreciably different, the discussions were surprisingly similar.

We begin with our finding that ex-combatants are more likely to view DDR favorably if they received useful job training as part of DDR. Participants quickly credited DDR for providing them with the job skills necessary to begin income-generating activities. Compared to nonDDR participants, one female Dinka participant who now runs a small tea stall explained, "My success is almost completely due to the training I received in DDR. Others are struggling, but I was able to start income-generating work right away." Other participants related DDR training to their specific current occupation, including barber training, tailoring, and running a small business like a tea stall or small restaurant. These remarks coincide well with an earlier study conducted by the Small Arms (2011), which highlighted the positive response from DDR participants to job-oriented reintegration packages.

We next turned to a discussion of security and firearms, seeking to better understand why DDR participants are less satisfied with DDR when they have major security concerns and when firearms are abundant in their communities. The discussions mirrored the complexity from our statistical analyses. Participants strongly dislike the widespread availability of firearms for two main reasons. First, they wish to end the "gun culture" in South Sudan, arguing that widespread firearms "undermine stability" and "threaten the fragile peace." Participants explained that firearms have become ingrained in their culture, harming stability, and development. Second, participants focused on their fear of youth, explaining that armed young men are "the main problem, causing all the vio-

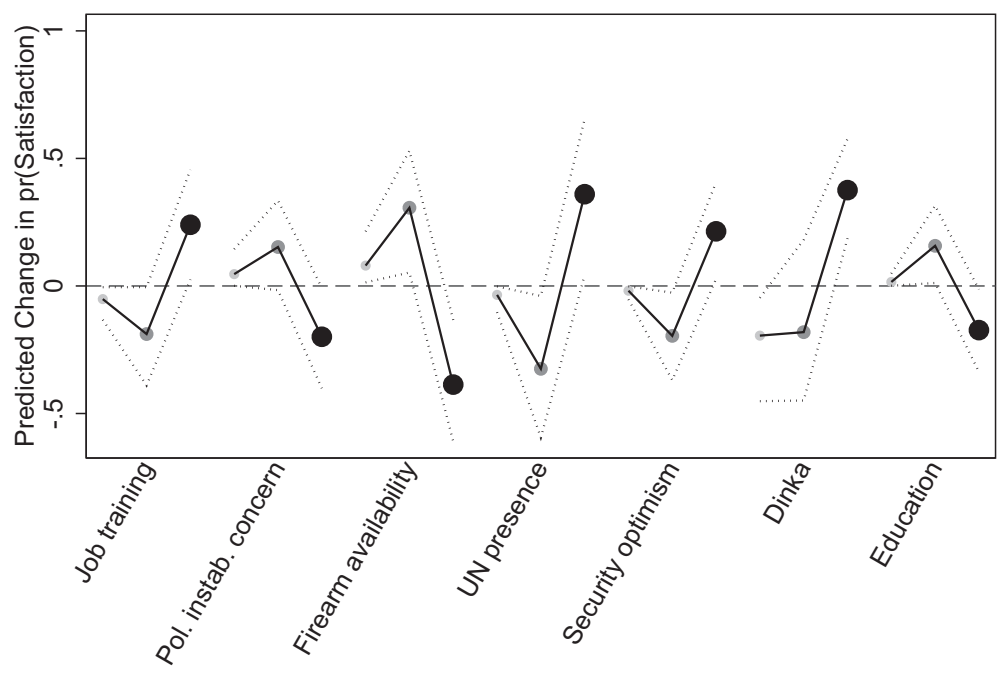

FIG. 2. Ex-combatant Satisfaction with DDR: Substantive Effects

Note. Values reveal first difference (FD) estimations in the likelihood of respondent having low (○), medium (○), and high (-) levels of satisfaction with DDR with $95 \%$ confidence intervals $(\ldots .$.$) .$

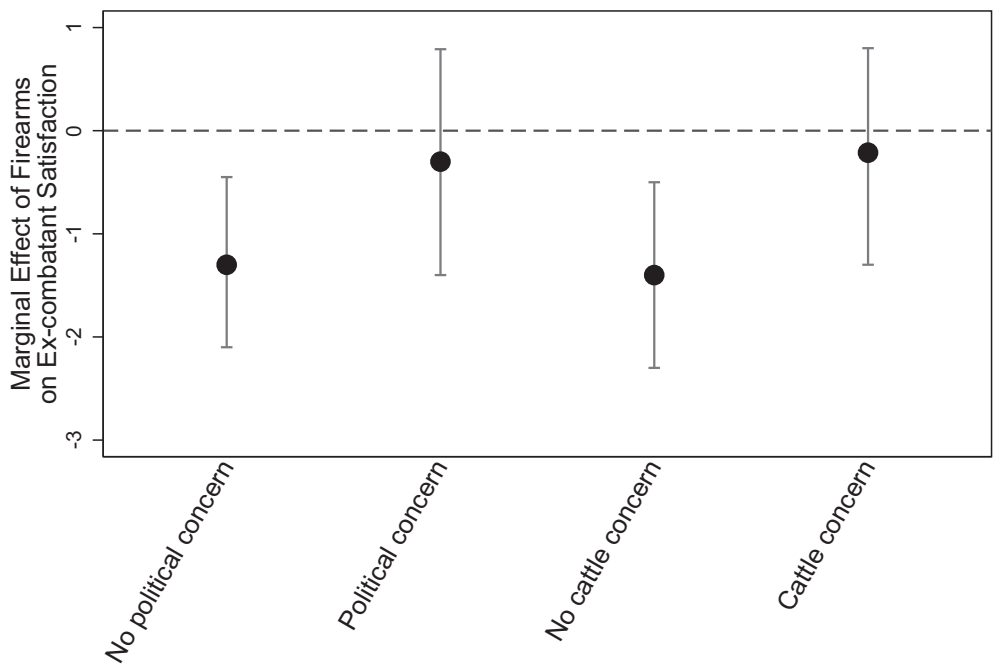

Fig. 3. Effect of Firearms Conditioned on Political and Cattle Rustling Concerns

Note. Values ( ) marginal effects with $95 \%$ confidence intervals $(|-|)$. Estimations come from Table 1, Models 2-3. 
lence, destruction, and hostility." This point mirrors a DFID Small Arms Survey paper on civilian disarmament (O'Brien 2009), which argues that violent youth threaten stability in South Sudan.

Like our survey findings, we found more complex answers among those who had concerns with political instability and cattle rustling. First, our focus group limited to youth focused on a unique path to explain why they favored firearms in places with rampant cattle rustling. These young men feared that they would be unable to make a living without a gun. Another main concern was the payment of dowries, as they saw cattle rustling as the only way to pay dowries due to the absence of hard currency. This viewpoint is consistent with Arnold and Alden's (2007) earlier study. Second, all other groups viewed firearms as a necessary evil in the absence of adequate protection from the government. People feared that they would be at the mercy of those with arms were firearms unavailable. Their primary fear was not a recurrence of civil war, but the need for protection from rival groups, armed youth, and cattle rustlers. Participants also related this fear to the inconsistent way in which ex-combatants were disarmed. Ethnic groups were not disarmed consistently, leaving some communities much more heavily armed than others. Further, the arms taken from combatants were not secured well, and many went to communities who sought arms due to political instability concerns.

The security concern related to firearms complemented the discussion on the positive presence of UN personnel. Our focus groups highlighted two factors to explain why they viewed DDR positively when the UN had a strong presence in their area. First, the most common response was that the UN provided security in an otherwise volatile environment. UN personnel limited the ability of youth to use violence and reduced cattle rustling. Consistent with our theory and the literature on external security guarantors, both were viewed as overwhelmingly positive roles by focus group participants. The second common response focused on factors outside of our theory and empirical analyses. Many respondents highlighted the positive role of NGOs in "sensitizing" youth about the benefits of peace. These groups held "peace meetings" with potentially violent groups to train them on how to solve conflicts without force. Thus, we see that external actors provide the necessary security as predicted in previous work, and also help shape norms of peaceful conflict resolution.

\section{Summary, Conclusion, and Implications}

All DDR programs seek to promote peace and stability through the management of weapons and sustainable reintegration of former combatants. While policy and scholarly communities have made great gains in our understanding of DDR, little existing work focuses on the participants to understand what makes DDR successful. Our study moves in this direction by analyzing the factors that make ex-combatants satisfied. Our theory focuses on participants' economic situations, security concerns, and ethnic integration. Our findings show that DDR participants were more satisfied when they received useful job training and when the UN had a strong presence in their area. Factors leading to dissatisfaction include security concerns and widespread availability of firearms.

Bolstered by evidence from our focus groups, we are comfortable making policy recommendations for South Sudan. Generalizing beyond this case (or any single case of DDR) should be done with caution, however, given wide variation on a number of important factors across DDR programs (Schulhofer-Wohl and Sambanis 2010:3, $27)$. In this sense, we fully agree with the "fundamental message" from Muggah's et al. (2009:20) edited volume on DDR, "...templates are to be avoided: context determines all." With this caveat in mind, one particular benefit of our study is that it keys in on specific paths for potential focus and reform. Many policy-mutable variables have a significant impact on DDR satisfaction (sustainable job training, instability, firearm availability, UN presence), while most policy-immutable variables have little effect (age, gender, rank). At a minimum, evidence from our study indicates that policymakers should consider DDR as an important process in shaping a postwar state's longterm stability.

Thus, we first urge policymakers to think long and hard about the disarmament phase of DDR. Consistent with Spear (2002), we find that there can be no "standard model" of disarmament. Instead, factors such as security concerns and social norms about firearms require attention. Our simplest findings indicate that satisfaction with DDR will increase as external security guarantors increase and as firearms are removed from society. However, the relationship between firearms, security concerns, and satisfaction proves complex. When security concerns are paramount, ex-combatants need arms for protection and will be less satisfied when they cannot protect themselves. Thus, policymakers essentially have two options when focusing on the disarmament phase. In the rare case that resources are plentiful, societies should be flooded with external security guarantors to assure that disarmed individuals feel secure without guns. In the more common resource-scare environment, policymakers should consider focusing on demobilization rather than disarmament. This recommendation has been followed in the past, including peace settlements that allowed rebels to retain arms in Yemen, Haiti, and Nepal. It is also consistent with Walter's (1997) study of the peace settlement with RENAMO in Mozambique, where groups were allowed to retain arms as a reassurance against reprisals. Although this may be a bitter pill to swallow, ex-combatants are likely to happily part with their guns only after their individual sense of security has been achieved.

Second, our evidence shows that job training is critical for ex-combatants to support DDR. This is heartening because job training not only predicts satisfaction, but it is also critical for the state's long-term economic development. While all DDR participants in our sample received job training, only $54 \%$ of them were unfortunately able to use their training to gain employment. Future DDR efforts should set a much higher target goal, working to link training with local-level economic needs.

Third, our findings related to ethnic tensions help provide lessons for the future, particularly when we consider the rising level of conflict in South Sudan today. Our specific finding in this regard showed that Dinkas were more satisfied with DDR than those from other ethnic groups. This is undoubtedly related to the Dinka-dominated SPLA calling many of the shots in the DDR process. Further, DDR did not take place in the states that were dominated by non-Dinka ethnic groups. Consistent with Muggah et al.'s (2009) critique of the uneven way in which DDR was conducted in South Sudan, therefore, it is wholly unsurprising to see ethnic tension leads to conflict in areas that were largely neglected by the peace process. 
For researchers, our study adds to a growing body of work that focuses on individuals both theoretically and empirically, helping us better understand how ex-combatants decide whether or not to take up arms and resume fighting (MacCulloch 2004; Humphreys and Weinstein 2007, 2008; Pugel 2009; Blattman and Annan 2009; Thyne and Schroeder 2012). Although the costs of such research are great, the consequences of civil wars justify the investment. And when combined with policy work focused on DDR implementation and scholarly work focused on post-conflict stability more generally, we are beginning to see puzzle pieces fitting together that will hopefully lead to a more peaceful future for states emerging from civil conflict.

\section{Appendix:}

TABLE A1. Summary Statistics and Bivariate Relationships

\begin{tabular}{|c|c|c|c|c|c|}
\hline & $\begin{array}{l}\text { Whole Sample } \\
N(\% \text { of Total }\end{array}$ & $\begin{array}{c}\text { Not Satisfied } \\
N \text { (\% of Row) }\end{array}$ & $\begin{array}{c}\text { Somewhat Satisfied } \\
N \text { (\% of Row) }\end{array}$ & $\begin{array}{c}\text { Very Satisfied } \\
N(\% \text { of Row })\end{array}$ & $\begin{array}{l}\text { Bivariate Relationship } \\
\qquad(p \text { Value })^{*}\end{array}$ \\
\hline \multicolumn{6}{|l|}{ Dependent variable } \\
\hline Satisfaction & $122(100)$ & $17(13.9)$ & $60(49.2)$ & $45(36.9)$ & \\
\hline \multicolumn{6}{|l|}{ Explanatory variables } \\
\hline \multicolumn{6}{|l|}{ Monthly income (H1a) } \\
\hline Mean $(S D)$ & $661.6(620.0)$ & $335.3(474.3)$ & $767.8(636.1)$ & $643.1(613.1)$ & $r=.093(.310)$ \\
\hline \multicolumn{6}{|l|}{ Job training $(\mathrm{H} 1 \mathrm{~b})$} \\
\hline $1=$ Train in DDR & $66(54.1)$ & $5(7.58)$ & $33(50.0)$ & $28(42.4)$ & Cr's V $=.210$ \\
\hline $0=$ No train in DDR & $56(45.9)$ & $12(21.4)$ & $27(48.2)$ & $17(30.4)$ & $\chi^{2}=5.4(.068)$ \\
\hline \multicolumn{6}{|l|}{ Political instab. concern (H2a) } \\
\hline 1 = Concerned & $28(23.0)$ & $10(35.7)$ & $12(42.9)$ & $6(21.4)$ & Cr's $V=.351 *$ \\
\hline $0=$ Unconcerned & $94(77.0)$ & $7(7.5)$ & $48(51.1)$ & $39(41.5)$ & $\chi^{2}=15.0(.001)$ \\
\hline \multicolumn{6}{|l|}{ Cattle rustling concern (H2a) } \\
\hline $1=$ Concerned & $30(24.6)$ & $11(36.7)$ & $10(33.3)$ & $9(30.0)$ & Cr's V $=.377^{*}$ \\
\hline $0=$ Unconcerned & $92(75.4)$ & $6(6.5)$ & $50(54.4)$ & $36(39.1)$ & $\chi^{2}=17.3(.001)$ \\
\hline \multicolumn{6}{|l|}{ Firearm availability (H2b) } \\
\hline $1=$ difficult to obtain & $66(54.1)$ & $7(10.6)$ & $23(34.9)$ & $36(54.6)$ & Tau-b $=-.384^{*}$ \\
\hline $2=$ somewhat easy & $37(30.3)$ & $0(0.0)$ & $31(83.8)$ & $6(16.2)$ & $(.001)$ \\
\hline $3=$ very easy & $19(15.6)$ & $10(52.6)$ & $6(31.6)$ & $3(15.8)$ & \\
\hline \multicolumn{6}{|l|}{ UN presence (H3) } \\
\hline Mean $(S D)$ & $5.62(6.11)$ & $2.09(0.98)$ & $6.80(6.64)$ & $5.39(6.03)$ & $r=.099(.279)$ \\
\hline \multicolumn{6}{|l|}{ Return to area of origin $(\mathrm{H} 4)$} \\
\hline $1=$ returned to origin & $90(73.8)$ & $13(14.4)$ & $45(50.0)$ & $32(35.6)$ & Cr's V $=.048$ \\
\hline $0=$ returned to other & $32(26.2)$ & $4(12.5)$ & $15(46.9)$ & $13(40.6)$ & $\chi^{2}=0.28(.871)$ \\
\hline \multicolumn{6}{|l|}{ Control variables } \\
\hline \multicolumn{6}{|l|}{ Security optimism } \\
\hline $1=$ sec. situation improving & $58(47.5)$ & $7(12.1)$ & $19(32.8)$ & $32(55.2)$ & Cr's V $=.048^{*}$ \\
\hline $0=$ sec. situation same $/$ worse & $64(52.5)$ & $10(15.6)$ & $41(64.1)$ & $13(20.3)$ & $\chi^{2}=0.28(.871)$ \\
\hline \multicolumn{6}{|l|}{ Dinka } \\
\hline $1=$ Dinka & $91(74.6)$ & $4(4.4)$ & $46(50.6)$ & $41(45.1)$ & Cr's V $=.496^{*}$ \\
\hline $0=$ Non-Dinka & $31(25.4)$ & $13(41.9)$ & $14(45.2)$ & $4(12.9)$ & $\chi^{2}=30.0(.001)$ \\
\hline \multicolumn{6}{|l|}{ Education } \\
\hline $1=$ some formal education & $75(61.5)$ & $16(21.3)$ & $35(46.7)$ & $24(32.0)$ & Cr's V $=.274 *$ \\
\hline $0=$ no education & $47(38.5)$ & $1(2.13)$ & $25(53.2)$ & $21(44.7)$ & $\chi^{2}=9.2(.010)$ \\
\hline \multicolumn{6}{|l|}{ Age } \\
\hline Mean $(S D)$ & $42.5(10.5)$ & $42.4(13.2)$ & $43.0(10.3)$ & $42.0(9.8)$ & $r=-.028(.761)$ \\
\hline \multicolumn{6}{|l|}{ Rank** } \\
\hline $1=$ Officer & $35(28.7)$ & $1(2.9)$ & $18(51.4)$ & $16(45.7)$ & Tau-c $=.164 *$ \\
\hline $0=$ Non-officer & $87(71.3)$ & $16(18.4)$ & $42(48.3)$ & $29(33.3)$ & $(.035)$ \\
\hline \multicolumn{6}{|l|}{ Male } \\
\hline $1=$ Male & $65(53.3)$ & $13(20.0)$ & $29(44.6)$ & $23(35.4)$ & Cr's V = .189 \\
\hline $0=$ Female & $57(46.7)$ & $4(7.0)$ & $31(54.4)$ & $22(38.6)$ & $\chi^{2}=4.6(.114)$ \\
\hline \multicolumn{6}{|l|}{ Killings } \\
\hline Mean $(S D)$ & $.152(.358)$ & $.009(.022)$ & $.247(.438)$ & $.079(.266)$ & $r=-.029(.754)$ \\
\hline \multicolumn{6}{|l|}{ Cereal production } \\
\hline Mean $(S D)$ & $14,440(12,727)$ & $17,021(16,492)$ & $14,950(12,335)$ & $12,786(11,697)$ & $r=-.113(.214)$ \\
\hline
\end{tabular}

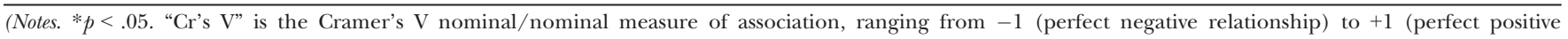
relationship).

*** "Rank" is an ordinal variable with eight categories ranging from private to colonel. We present only a dichotomous officer/non-officer split in the table above for ease of presentation and space concerns. Bivariate summary statistics for rank (Tau-c and associated p value) are for the original ordinal ranking used in the analyses). 


\section{References}

Aleu, Philip T. (2010) Jonglei Pastorals Warn of Rearmament if Government Fails to Provide Security. Sudan Tribune. February 22. Available at http://www.sudantribune.com/spip.php?page= imprimable\&id_article=34214 (Accessed June 6, 2013).

Alusala, Nelson, AND Dominigue Dye. (2010) Reintegration in Mozambique: An Unresolved Affair. ISS Paper 217. Pretoria, South Africa: Institute for Security Studies.

Arnold, Matthew B., And Chris Alden. (2007) This Gun is our Food: Demilitarizing the White Army Militias in South Sudan. Oslo: Norwegian Institute of International Affairs (NUPI) Working Papers. Available at http://www.einiras.org (Accessed April 5, 2013).

Bensahel, Nora, Olga Oliker, and Heather Peterson. (2009) Improving Capacity for Stabilization and Reconstruction Operations. Monograph 852. Santa Monica, CA: Rand Corporation.

Berdal, Mats R. (1996) Disarmament and Demobilisation after Civil Wars. Adelphi Paper No 303. Oxford: Oxford University Press.

Beswick, Stephanie. (2004) Sudan's Blood Memory: The Legacy of War, Ethnicity, and Slavery in Early South Sudan. Rochester: University of Rochester Press.

Blattman, Chris, and Jeanie Annan. (2009) The Reintegration of Child and Youth Combatants in Northern Uganda: Myth and Reality. In Security and Post-Conflict Reconstruction Dealing with Fighters in the Aftermath of War, edited by Robert Muggah. New York: Routledge.

Brancati, Dawn, and Jack L. Snyder. (2012) Time to Kill: The Impact of Election Timing on Postconflict Stability. Journal of Conflict Resolution 57 (5): 822-853.

Branch, Adam, and Zachariah C. Mampilly. (2005) Winning the War, but Losing the Peace? Journal of Modern African Studies 43 (1): 1-20.

Brethreld, Julie. (2010) Unrealistic Expectations: Current Challenges to Reintegration in Southern Sudan. HSBA Working Paper No. 21. Geneva: Small Arms Survey.

Caruso, Raul, Prabin B. Khadka, Ilaria Petrarca, and Roberto Ricciti. (2012) Do UN Troops Secure Crops? Evidence from South Sudan. Working Paper Series, Department of Economics, University of Verona.

Colletta, Nat J., and Robert Muggah. (2009) Rethinking Post-War Insecurity: From Interim Stabilization to Second Generation Security Promotion. Journal of Humanitarian Assistance 9 (4): 425-453.

Collier, Paul, and Anke Hoeffler. (2004) Greed and Grievance in Civil War. Oxford Economic Papers 56: 563-595.

Collier, Paul, lani Elliott, Havard Hegre, Anke Hoeffler, Marta Reynal-Querol, and Nicholas Sambanis. (2003) Breaking the Conflict Trap: Civil War and Development Policy. Washington, DC: The International Bank for Reconstruction and Development/The World Bank.

Collier, Paul, Anke Hoeffler, and Mans Soderbom. (2008) Postconflict Risks. Journal of Peace Research 45 (4): 461-478.

Gettleman, Jefrrey. (2012) Born in Unity, South Sudan is Torn Again. New York Times, 12 Jan.

Hartzell, Caroline, and Matthew Hoddie. (2003) Institutionalizing Peace: Power Sharing and Post-Civil War Conflict Management. American Journal of Political Science 47 (2): 318-332.

Humphreys, MacArtan, and Jeremy M. Weinstein. (2007) Demobilization and Reintegration. Journal of Conflict Resolution 51 (4): 531-567.

Humphreys, MacArtan, and Jeremy M. Weinstein. (2008) Who Fights? The Determinants of Participation in Civil War. American Journal of Political Science 52 (2): 436-455.

IRIN (2012) DRC: North Kivu in Turmoil Again. 16 May. Available at http:/ /www.irinnews.org (Accessed January 5, 2014).

Jennings, Kathleen M. (2007) The Struggle to Satisfy: DDR Through the Eyes of Ex-Combatants in Liberia. International Peacekeeping 14 (2): $1-15$.

Kalyvas, Stathis. (2006) The Logic of Violence in Civil War. New York: Cambridge University Press.

Kilroy, Walt. (2012) From Conflict to Ownership: Participatory Approaches to the Reintegration of Ex-combatants in Sierra Leone and Liberia. PhD diss. Dublin City University.

King, Gary, Michael Tomz, and Jason Wittenberg. (2000) Making the Most of statistical Analyses: Improving Interpretation and Presentation. American Journal of Political Science 44 (2): 347-361.
Kingma, KeEs. (1997) Demobilization of Combatants after Civil Wars in Africa and their Reintegration into Civilian Life. Policy Sciences 30 (3): 151-165.

Kingma, Kees. (2002) Demobilization, Reintegration and Peacebuilding in Africa. In Recovering from Civil Conflict: Reconciliation, Peace and Development, edited by Edward Newman, and Albrecht Schnabel. Portland: Frank Cass.

Knight, Mark, and Alapslan Ozerdem. (2004) Guns, Camps and Cash: Disarmament: Demobilization and Reinsertion of Former Combatants in Transitions from War to Peace. Journal of Peace Research 41 (4): 499-516.

Kron, Josh. (2010) Peace Hovers in Sudan, but Most Soldiers Stay Armed. New York Times, 30 December.

Lamb, Guy, and Dominioue Dye. (2009) Security Promotion and DDR: Linkages Between ISMs, DDR, and SSR Within a Broader Peacebuilding Framework. CIDDR Background Paper, Washington, DC: World Bank.

MacCulloch, Robert. (2004) The Impact of Income on the Taste for Revolt. American Journal of Political Science 48 (4): 830-848.

Mores, Magali. (2013) Overview of Corruption and Anti-corruption in South Sudan. Transparency International. Available at http:// www.transparency.org (Accessed May 5, 2013).

Muggah, Robert. (2010) Innovations in Disarmament, Demobilization and Reintegration Policy and Research: Reflections on the Last Decade. NUPI Working Paper 774. Oslo, Norway: Norwegian Institute of International Affairs.

Muggah, Robert, and Jon Bennett. (2009) Context Matters in Ethiopia: Reflections on a demobilization and Reintegration Programme. In Security and Post-Conflict Reconstruction Dealing with Fighters in the Aftermath of War, edited by Robert Muggah. New York: Routledge.

Muggah, Robert, Desmond Molloy, and Maximo Halty. (2009) (Dis)integrating DDR in Sudan and Haiti? Practitioners' Views to Overcoming Integration Inertia. In Security and Post-Conflict Reconstruction Dealing with Fighters in the Aftermath of War, edited by Robert Muggah. New York: Routledge.

National Bureau of Statistics (NBS). (2009-2011) South Sudan Statistical Yearbook. Available at http://ssnbs.org/ (Accessed November 7, 2013).

O'Brien, Adam. (2009) Shots in the Dark: The 2008 South Sudan Civilian Disarmament Campaign. Geneva: Small Arms Survey.

Office for the CoOrdination of Humanitarian AfFairs (OCHA). (2009-2011) South Sudan. Available at http://www.unocha.org/ (Accessed July 5, 2013).

Paris, Roland. (2001) The Faulty Assumption of Peacebuilding. In Turbulent Peace The Challenges of Managing International Conflict, edited by Chester A. Crocker, Fen O. Hampson, and Pamela Aall. Washington, DC: United States Institute of Peace.

Paris, Roland. (2004) At War's End: Building Peace after Civil Conflict. Cambridge, UK: Cambridge University Press.

Pendle, Naomi. (2012) South Sudan: Rearmament in Warrap State. African Arguments, 27 March.

Pugel, James. (2009) DDR in Liberia: Reviewing the Gap between Goals and Outcomes. In Security and Post-Conflict Reconstruction Dealing with Fighters in the Aftermath of War, edited by Robert Muggah. New York: Routledge.

Pun, Kiran. (2012) Ex-PLA Avoid Integrating back into Home Villages. República, 19 Sept.

Restrepo, Jorge A., and Robert Muggah. (2009) Colombia's Quiet Demobilization: A Security Dividend? In Security and Post-Conflict Reconstruction Dealing with Fighters in the Aftermath of War, edited by Robert Muggah. New York: Routledge.

Schulhofer-Wohl, Jonah, AND Nicholas SAmbanis. (2010) Disarmament, Demobilization, and Reintegration Programs: An Assessment. Folke Bernadotte Academy Research Report. Sandöverken, Sweden.

Small Arms, Survey. (2011) Women's Security in South Sudan." Sudan Human Security Baseline Assessment (HSBA). Available at http:// www.smallarmssurveysudan.org (Accessed February 4, 2014).

South Sudan Statistical Yearbook. (2011) The Republic of South Sudan National Bureau of Statistics. Available at http://ssnbs.org (Accessed August 2, 2013).

Spear, Johnna. (2002) Disarmament and Demobilization. In Ending Civil Wars: The Implementation of Peace Agreements, edited by Stephen J. 
Stedman, Donald Rothchild, and Elizabeth M. Cousens. Boulder, CO: Lynne Rienner.

Spear, JoAnna, and Bernard Harborne. (2010) Improving Security in Violent Conflict Settings. Background Paper for World Development Report.

Stedman, Stephen J. (1997) Spoiler Problems in Peace Processes. International Security 22 (2): 5-53.

Stedman, Stephen J., Donald Rothschild, and Elizabeth M. Cousens. (2002) Ending Civil Wars: The Implementation of Peace Agreements. Boulder, CO: Lynne Rienner.

STHLM Policy Group. (2010) South Sudan DDR Programme Review Report. Stockholm: STHLM Policy Group.

Stockholm Initiative on DDR (SIDDR). (2006) Final Report. Available at http://www.government.se/sb/d/4890/a/64356 (Accessed March 16, 2013).

Thyne, Clayton L., And Ryan D. Schroeder. (2012) Social Constraints and Civil War: Bridging the Gap with Criminological Theory. Journal of Politics 74 (4): 1066-1078.

Tomz, Michael, Jason Wittenberg, and Gary King. (2003) CLARIFY: Software for Interpreting and Presenting Statistical Results. Journal of Statistical Software 8 (1): 1-30.
UN High Commissioner for Refugees (UNHCR). (2010) Sudan Statistic Snapshot. Available at http://www.unhcr.org/pages/ 49e483b76.html (Accessed March 4, 2013).

UN IDDRS. (2010) Operational Guide to the Integrated, Disarmament, Demobilization and Reintegration Standards (IDDRS).

Verheul, AdriaAn. (2011) Managing DDR Risks in Sudan: A Field Perspective. In Monopoly of Force: The Nexus of DDR and SSR, edited by Melanne A. Civic, and Michael Miklaucic. Washington, DC: National Defense University Press.

Walter, Barbara F. (1997) The Critical Barrier to Civil War Settlement. International Organization, 51 (03): 335-364.

Walter, Barbara F. (1999) Designing Transitions from Civil War: Demobilization, Democratization, and Commitments to Peace. International Security 24 (1): 127-155.

Walter, Barbara F. (2002) Successful Settlement of Civil Wars. Princeton, NJ: Princeton University Press.

Walter, Barbara F., And Jack L. Snyder, Eds. (1999) Civil Wars, Insecurity, and International Intervention. New York: Columbia University Press.

Wilen, NinA. (2013) Identifying the Spoilers in the Security Sector Reform-disarmament Demobilisation and Reintegration process in the Congo. Defense E Security Analysis 29 (2): 117-127. 